\title{
TERRITORIALIDADE DA INFORMAÇÃO, PELAS REDES TELEFÔNICA, NA CIDADE DE SENADOR CANEDO EM GOIÁS: ESTUDO DE CASO
}

\author{
Territoriality of the information, by the telephone networks, in the city of Senador Canedo \\ in Goiás: case study
}

\author{
João Dib Filho * \\ Vitor Ribeiro Filho ** \\ Antônio Henrique Capuzzo Martins ***
}

\begin{abstract}
${ }^{*}$ Docente do Instituto Federal de Goiás - joao.dib.f@gmail.com. ** Docente da Universidade Federal de Uberlândia - vitor.ribeiro@ufu.br. *** Docente do Instituto Federal de Goiás - capuzzoifg@gmail.com.
\end{abstract}

\begin{abstract}
Resumo: Verificando as estruturas da cidade, percebe-se a condição e presença de perfis de renda diferenciados, o que leva a avaliação, a um paralelo que pode representar melhor a própria diferença da renda (ou aparência de renda) nas áreas cobertas pelo capital, aqui representados pelas operadoras de telefonia (fixa e até mesmo as de celulares) e pelas manchas de cobertura das mesmas. A mancha de cobertura em análise foi tirada do link da Anatel, que é o órgão que representa o Estado/União, como agência reguladora que fiscaliza o segmento de telecomunicações, e consequentemente, das áreas de cobertura estabelecidas pelas empresas de telefonia aqui tratadas.
\end{abstract}

Palavras-chave: Redes telefônicas; Espaços Urbanos; Senador Canedo.

\begin{abstract}
The paper reports a study case, checking the city's structures, we see the condition and presence of different income profiles, which leads the assessment, a parallel that can better represent the own income difference (or income appearance) in the areas covered by the capital here represented by the telephone operators (fixed and even mobile) and for the same coverage of stains. The spot coverage analysis was taken from Anatel link, which is the body representing the State / Union as a regulatory agency that oversees the telecommunications segment, and consequently, the coverage areas established by telephone companies addressed here.
\end{abstract}

Key-words: Telephone Networks; Urban Spaces; Senador Canedo.

\section{Introdução}

O crescimento da cidade de Goiânia há muito ultrapassou os limites municipais, compondo uma mancha urbana que inclui várias cidades, fazendo com que, hoje, nela se inclua o segundo maior município do Estado de Goiás, o município de Aparecida de Goiânia. No todo, Goiânia e seu entorno concentram uma população urbana.

Essa expansão urbana fez com que antigos distritos se tornassem municípios autônomos, ou bairros e municípios autônomos se tornassem cidades dormitórios ou, ainda, literalmente, bairros, configurando um processo parecido com aquele observado pelo arquiteto Flávio Vilaça na cidade de São Paulo, de que ela é devoradora de cidades e uma produtora de bairros (VERGARA; ACCORSI, 1999).

Ao final do século, Goiânia e seu entorno concentram uma população de, aproximadamente, 1,5 milhão de habitantes e o que se afigurava como um aglomerado urbano toma, agora, a forma 
conurbada, eliminando-se os vazios urbanos. 0 que não significa o fim da expansão da periferia, mas a sua redefinição dada pelo surgimento dos enclaves. Provocando o seu deslocamento além dos núcleos urbanos conurbados ou a sua recriação nas fímbrias da cidade-metrópole, como se verifica na região sul de Goiânia, onde se desenvolveram vários bairros sob a influência do processo de ocupação acelerada da capital e completamente inseridos na sua dinâmica.

O crescimento demográfico - decorrente da migração de pessoas de outras Regiões brasileiras -, a fragmentação sócio espacial e a necessidade da reforma urbana - como pré-requisito para democratização da cidade -, fazem da região metropolitana de Goiânia um rico objeto de pesquisa.

Este crescimento transforma as cidades, em potencial, em grandes objetos de riqueza das incorporadoras / imobiliárias onde, através de influências políticas, acabam se favorecendo das leis aprovadas, inclusas nos planos diretores, principalmente no quesito limite de expansão urbana.

A origem de Senador Canedo (Figura 1) está relacionada à Goiânia, com a estrada de ferro da Rede Ferroviária Federal. 0 crescimento da cidade ocorreu na trilha aberta na construção da ferrovia, e as primeiras famílias trabalhadoras eram oriundas do estado de Minas Gerais e Bahia.

O nome da cidade é uma homenagem ao senador Antônio Amaro da Silva Canedo, primeiro representante do estado de Goiás em cenário nacional. Em 1953, o povoado foi elevado à condição de distrito de Goiânia e em 1988, a Assembleia Legislativa de Goiás aprovou a emancipação do município. Foi sancionada como Lei 10.435 de 09 de janeiro de 1988 pelo então governador Henrique Santillo. Servindo de cidade dormitório para Goiânia, ocorreu no início da década de 90 uma explosão populacional, dobrando a população em apenas 5 anos, conforme contagem do IBGE em 1996.

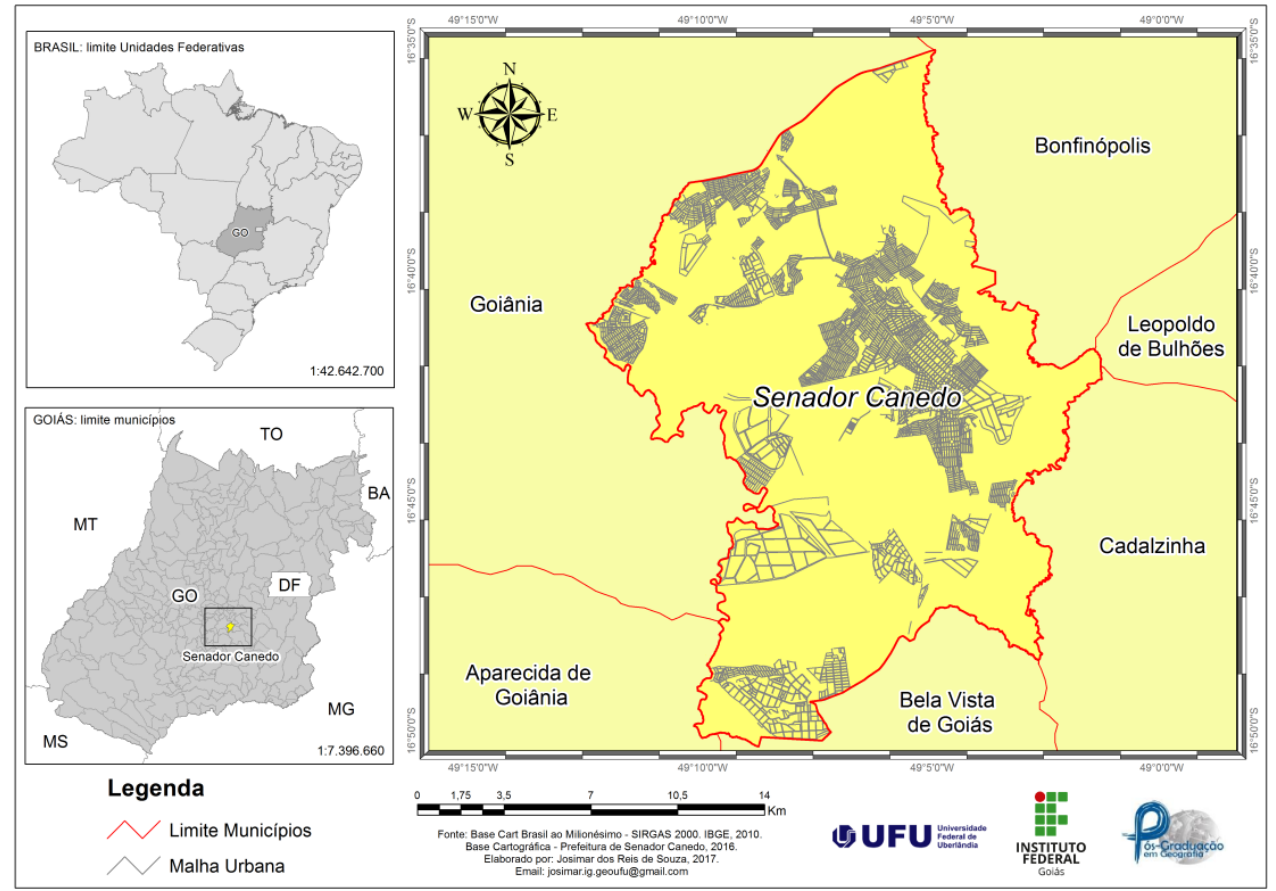

Figura 1 - Mapa de localização do município de Senador Canedo - Go Fonte: IBGE, 2017.

Sua posição geográfica privilegiada e o terminal ferroviário existente atraíram empresas e o município iniciou o seu desenvolvimento urbanístico.

A chegada do terminal da Transpetro (subsidiária da Petrobrás) mudou a cidade, gerando maior atratividade e riqueza ao Município, o que lhe permite avançar nos aspectos sociais e urbanos, onde se destacam a criação de escolas, centros de saúde e a pavimentação, que abrange mais de $70 \%$ do 
sistema viário da cidade.

Senador Canedo, mesmo desenvolvendo como visto, continua servindo parcialmente como cidade dormitório de Goiânia, já tendo iniciado o processo de conurbação (união de manchas urbanas). Apesar do desenvolvimento econômico ter sido intenso nos últimos anos, o IDH de 0,701 e taxa de mortalidade no patamar de 25/mil nascidos vivos indicam que o Município está na média do estado, não tendo tido tempo ainda de transportar sua pujança econômica para a área social.

O município apresenta três manchas urbanas de importância: a Sede, distante $8 \mathrm{~km}$ da divisa com Goiânia, e outras duas que já formam conurbação com Goiânia, o Distrito de Jd. Das Oliveiras/Matinha, situado ao norte no eixo da rodovia GO 010, e o Distrito de Galvão/Valéria Perrilo no eixo do rodovia GO 403. A expansão urbana deve se concentrar nas margens do GO 403. No curto/médio prazo ao norte da rodovia, fechando as manchas urbanas existentes e, no médio/longo prazo ao sul da rodovia, entre esta e a G0 019 (Tabela 1).

Tabela 1 - Porte das Manchas Urbanas

\begin{tabular}{|l|c|c|}
\hline Local & $\begin{array}{c}\text { Sist. Viário } \\
(\mathbf{k m})\end{array}$ & $\begin{array}{c}\text { Domicílios } \\
(\mathbf{m i l} \text { unid) }\end{array}$ \\
\hline Sede & 230 & 11,7 \\
\hline Galvăo/V.Perrilo & 45 & 2,7 \\
\hline Jd. Oliveiras/Matinha & 55 & 4,5 \\
\hline Outras & $\mathrm{Nd}$ & 1,1 \\
\hline Total & 330 & 20,0 \\
\hline
\end{tabular}

Fonte: Prefeitura do Município de Senador de Canedo - GO, 2013.

Na contagem populacional do IBGE, em 2007, foi registrada uma população de 70,8 mil habitantes. Apesar de ter ficado aquém das expectativas4 e apresentar a mesma tendência declinante que se observa no Estado, a taxa de crescimento populacional ainda é bem alta $(4,2 \%$ ao ano). A projeção da população no horizonte do projeto é de 173 mil habitantes, conforme Tabela 2. A taxa de urbanização também é alta (>93\%), com tendência de crescimento, portanto, para fins deste estudo, considerasse urbana toda população do Município (Gráfico 1).

Tabela 2 - População de Goiás e Senador Canedo - GO até 2040

\begin{tabular}{|c|c|c|c|c|}
\hline \multirow{2}{*}{ Ano } & \multicolumn{2}{|c|}{ Estado de Goiás } & \multicolumn{2}{c|}{ Senador Canedo } \\
\cline { 2 - 5 } & Pop. (mil Hab) & Taxa (\% aa.) & Pop (mil Hab) & Taxa (\% aa.) \\
\hline 1980 & 3.107 & & & \\
\hline 1991 & 3.979 & $2,3 \%$ & 22 & \\
\hline 1996 & 4.640 & & 44 & \\
\hline 2000 & 4.953 & $1,6 \%$ & 53 & $4,7 \%$ \\
\hline 2007 & 5.840 & $2,4 \%$ & 71 & $4,2 \%$ \\
\hline 2010 & 6.162 & $1,8 \%$ & 79 & $3,9 \%$ \\
\hline 2020 & 7.115 & $1,4 \%$ & 108 & $3,1 \%$ \\
\hline 2030 & 8.016 & $1,2 \%$ & 140 & $2,6 \%$ \\
\hline 2040 & 8.855 & $1,0 \%$ & 173 & $2,2 \%$ \\
\hline
\end{tabular}

Fonte: Censos do IBGE e PNAD (2005).

Conforme o censo de 2010 o rendimento nominal mediano mensal per capita dos domicílios particulares permanentes - urbana é de $\mathrm{R} \$ 443,33$. 0 município tem a característica de maior uniformidade de renda, ou seja, os domicílios mais frequentes estão entre 2 a 5 salários mínimos (Gráfico 2). 


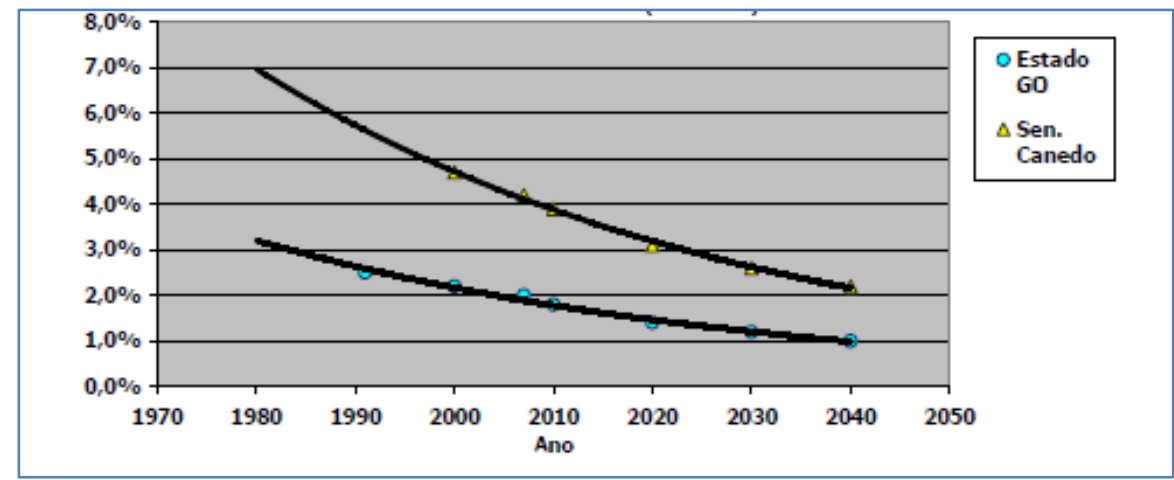

Gráfico 1 - Taxa de Crescimento (\% ao Ano)

Fonte: PNUD, 2013.

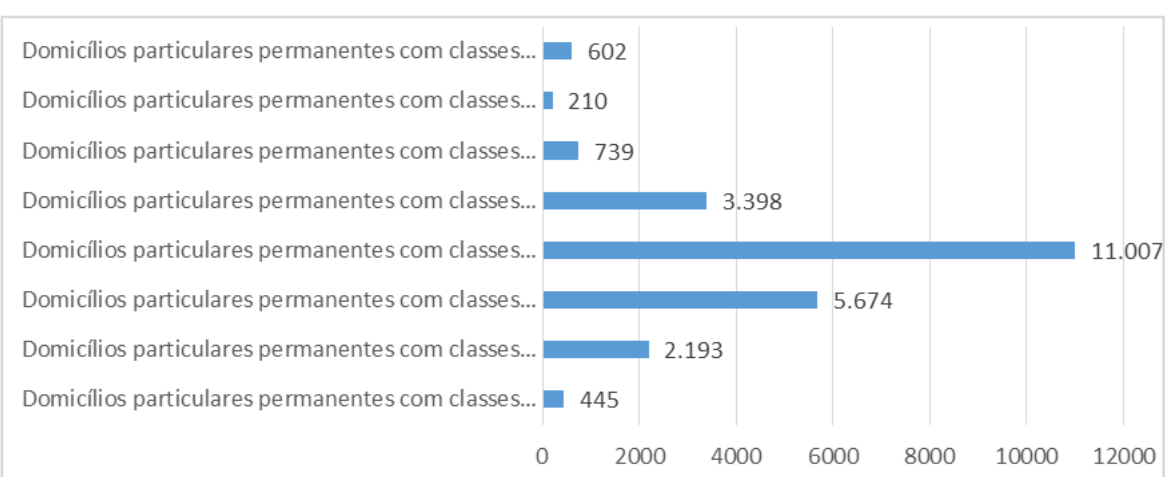

Gráfico 2 - Rendimento Domicílios particulares permanentes das 24.268 unid. domiciliares

Fonte: Censo IBGE, 2010 e PNUD, 2013.

Em pesquisa realizada pelo Instituto Brasileiro de Geografia e Estatística (IBGE), a cidade de Senador Canedo aparece, entre as cidades brasileiras, com um de seus melhores Índices de Desenvolvimento Humano Municipal (IDHM), alcançando a média 0,701 obtendo a classificação Alto Desenvolvimento Humano (Gráfico 3), de acordo com a classificação do Programa das Nações Unidas para o Desenvolvimento (PNUD). 0 índice intitulado "Atlas do Desenvolvimento do Brasil 2013", considera indicadores de longevidade (saúde), renda e educação.

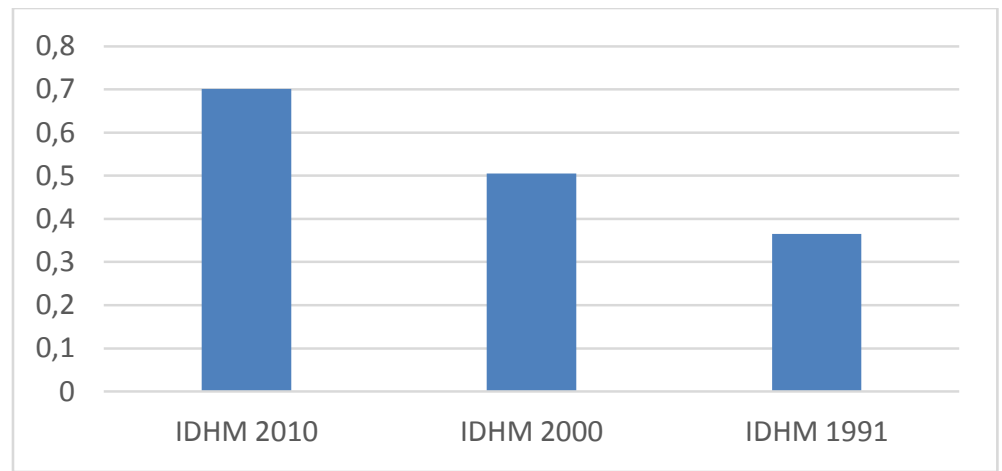

\footnotetext{
Gráfico 3 - Índice de Desenvolvimento Humano Municipal - IDHM

Fonte: PNUD, 2013.
} 


\section{Crescimento da infraestrutura em função da especulação imobiliária}

A especulação imobiliária, portanto, caracteriza-se pela distribuição coletiva dos custos de melhoria das localizações, ao mesmo tempo em que há uma apropriação privada dos lucros provenientes dessas melhorias. Essas melhorias que acabam valorizando os terrenos podem dar-se de muitas formas; as mais comuns referem-se à provisão de infraestrutura (água, esgoto, energia), serviços urbanos (creches, escolas, grandes equipamentos urbanos) e às melhorias realizadas nas condições de acessibilidade (abertura de vias, pavimentação, sistema de transporte, etc.). Na criação de novos loteamentos é respeitado as diretrizes do Plano Diretor e suas Cartas Derivadas, que não obriga a implantação de nenhum serviço de telefonia. Desta forma o estado, que exerce o papel de regulador, e não obrigam as incorporadoras a executar as obras de infraestrutura de telefonia necessária, ficando ao interesse e o custo para as operadoras, a implantação tanto da infra quanto da operação.

A complexidade de implantação de qualquer sistema de telefonia, poderia ser minimizada, em função tanto dos trâmites legais, quanto de parte da infraestrutura necessária, pois é possível de ter aproveitamento de ambas, em função da implantação da rede de energia, que é item obrigatório na aprovação de novos loteamentos.

Hoje não é possível debater a sociedade sem mencionar o papel da informação e das telecomunicações, sejam nas relações de trabalho, negócios, vida cotidiana, política, ambiente ou mesmo na organização territorial e na produção de novas infraestruturas técnicas.

Seu significado extrapola o simples fato de levar a comunicação a distintas partes do mundo para assumir a posição de base de sustentação da sociedade capitalista e a formação de uma "sociedade da informação" (CASTELLS, 2003).

Formas cada vez mais globalizadas das técnicas são difundidas a todo o momento, definindo, por outro lado, o conjunto de transformações e desigualdades socioespaciais que cada lugar, por meio das relações sociais estabelecidas entre múltiplos agentes, acolhe e sintetiza de forma contraditória. As Telecomunicações sustentada em especial, pelo papel que assume a informação na produção territorial.

A informação, nessa perspectiva, ganha forte expressividade nos estudos voltados à compreensão da sociedade, cabendo, dentre as diferentes possibilidades de análise territorial, demarcar as relações de poder, estratégias e conflitos estabelecidos com fundamento corporativo ou banal no seu uso. As telecomunicações tem um papel importante na divulgação da informação, que se difunde pelo território.

Por outro lado, é preciso ter em mente que a interpretação das telecomunicações pode ser útil para a compreensão e apreensão das desigualdades e transformações socioespaciais recentes, em que se inserem o mundo e a sociedade como totalidades. Dessa maneira, é impossível negar o papel da informação e das telecomunicações na organização do território, em distintas partes do mundo. No Brasil, essa afirmação tem ganhado cada vez mais importância ao verificar as transformações socioespaciais (Jurado da Silva, 2011) que o país vem passando nos últimos anos, com a ampliação da densidade técnica, científica e informacional em diversas regiões.

Dentro do exposto anteriormente, nos deparamos com os termos "sociedade em rede" e "meiotécnico-científico-informacional".

"Os elementos do espaço seriam os seguintes: os homens, as firmas, as instituições, o chamado meio ecológico e as infraestruturas. Os elementos do espaço seriam os seguintes: os homens, as firmas, as instituições, o chamado meio ecológico e as infraestruturas. Os homens são elementos do espaço, seja na qualidade de fornecedores de trabalho, seja na de candidatos a isso, trate-se de jovens, de desempregados ou não empregados. A verdade é que tanto os jovens quanto os ocasionalmente sem emprego ou os já aposentados, não participam diretamente da produção, mas o 
simples fato de estarem presentes no lugar tem como consequência a demanda de um certo tipo de trabalho para outros. Esses diversos tipos de trabalho e de demanda são a base de uma classificação do elemento homem na caracterização de um dado espaço. A demanda de cada indivíduo como membro da sociedade total é respondida em parte pelas firmas e em parte pelas instituições. As firmas têm como função essencial a produção de bens, serviços e ideias. As instituições por seu turno produzem normas, ordens e legitimações. 0 meio ecológico é o conjunto de complexos territoriais que constituem a base física do trabalho humano. As infraestruturas são o trabalho humano materializado e geografizado na forma de casas, plantações, caminhos, etc." (SANTOS, 1988).

\section{Levantamento de Campo}

Foram realizados testes de sinal e verificação visual da presença de serviços telefônicos das operadoras de telefonia fixa, e de sinal de voz/dados para as operadoras de telefonia celular, a fim de verificar e certificar se a área de cobertura disponibilizada no site da Anatel, atenderia realmente ao que está informado pela mesma. Com isto, poderá verificar se, o atendimento para quem está fora da cobertura é bom, precário ou até mesmo inexistente.

No caso das redes de telefonia fixa, a observação, feita em loco, considerou a própria existência de estrutura de cabos de rede fixa como indicativo para oferta de serviços. Na Rede Móvel, foram utilizados aparelhos celulares contendo linhas das quatros operadoras que detém os direitos exploratórios de serviços na cidade já citada, para tanto, e adicionalmente aos sinais de cada operadora presentes nos aparelhos, foi utilizado a ferramenta conhecida como Opensignal (conforme figura 9), que tem os dados da ANATEL como base para verificação de cobertura e que também oferece indicativos para a verificação dos sinais de voz e dados.

Dentro das áreas selecionadas para a realização do levantamento, que fazem parte do distrito sede do Município de Sanador Canedo, foi feita a proposição de quadrantes contemplados com certa simetria (conforme figura 2). Foram identificados 13 pontos, distribuídos em duas micro áreas (entende-se como duas porções de loteamentos separados e executados em períodos diferentes), distantes uma da outra, para então realizar as observações de disponibilidade de serviços de telefonia fixa e Móvel observando neles, a presença de rede fixa e a disponibilidade/qualidade dos sinais de voz e dados, respectivamente.

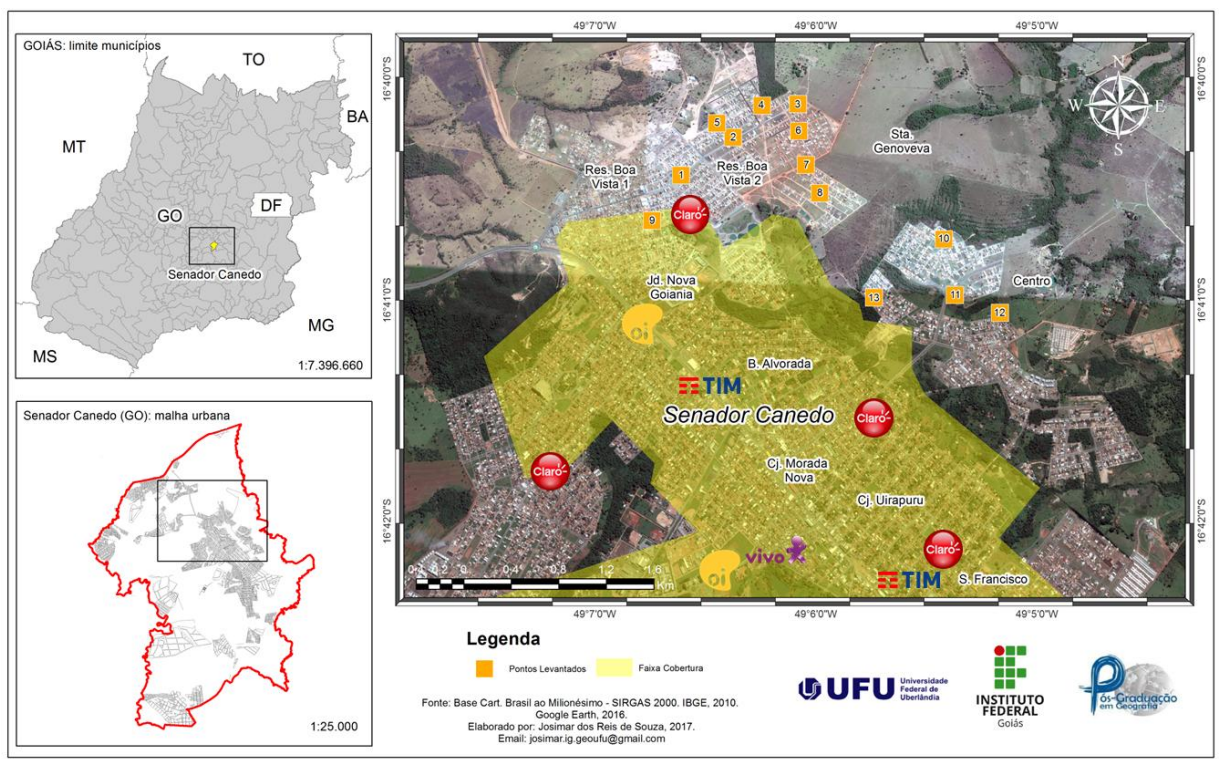

Figura 2 - Senador Canedo (G0): malha de cobertura de ERBS Fonte: ANATEL, 2016. 
Para certificação das redes celulares, foram aplicadas as verificações dos sinais de voz e de dados nos aparelhos celulares, foi também aplicado o uso de aplicativo (sendo este utilizado por técnicos de operadoras celulares) que também utiliza a área de cobertura disponibilizada pela Anatel, e pode ser confirmado a ausência de cobertura nas áreas externas às áreas identificadas como tendo cobertura. E ainda, foi percebido que até mesmo nos limites internos destas áreas, os serviços de dados das operadoras não foram percebidos como bons, ou seja, pode verificar que ali também tem uma condição ruim de acesso a rede de dados (Figura 3).

Nas áreas levantadas no setor (INICIAL), no que tange as redes de telefonia fixa, foi visto que a rede de cobertura destas são praticamente coincidentes com a área de cobertura de celular, e para a parte atendida, foi visto praticamente o atendimento de uma única operadora de telefonia fixa, o que demonstra a divergência de interesses do capital em atender uma fração da região com característica de renda inferior até mesmo com a renda mediana da cidade. E que ao seguir para as regiões não atendidas, fica ainda mais forte a imagem de que a ocupação social se dá com famílias de renda menor do que aquelas presentes na porção inicialmente atendida pela operadora de telefonia fixa. Ainda nesta fração geográfica do setor INICIAL, para os celulares, em resultado de cobertura, o resultado é praticamente o mesmo para todas elas, onde o sinal variou entre ausência total de acesso à DADOS até um sinal tido como ruim, com uma oscilação constante, em que em frações de segundos, os sinais passavam de ruim à falta total do sinal. 0 resultado do levantamento é apresentado no Quadro 1.

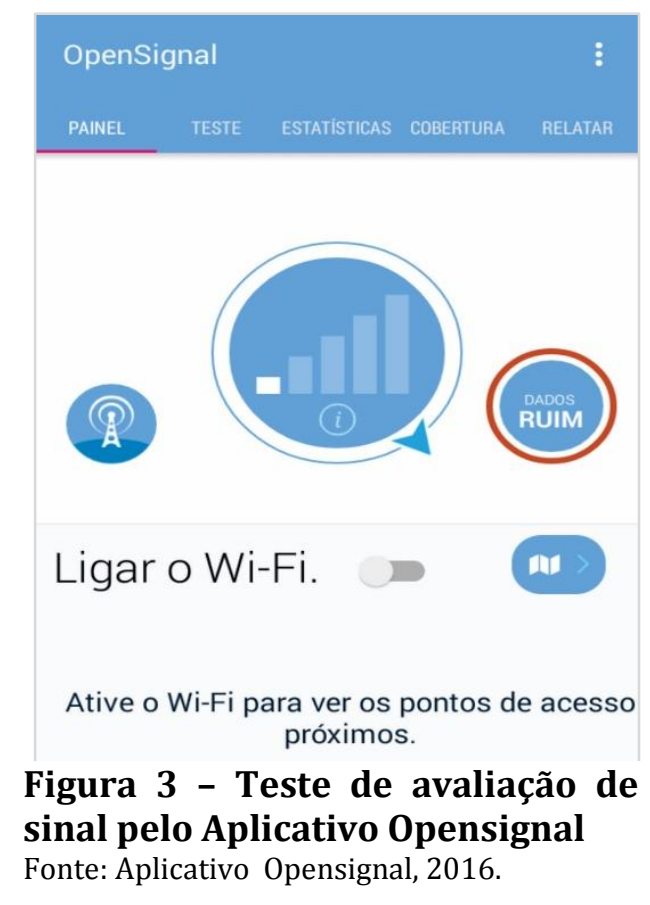

O quadro foi preenchido com os dados, das redes fixa e móvel, identificados pelo levantamento de campo. 


\begin{tabular}{|c|c|c|c|}
\multicolumn{4}{|c}{ Quadro 1 - Resultados Obtidos da Avaliação de Campo } \\
\cline { 2 - 4 } PONTOS & \multicolumn{3}{c|}{ SINAL } \\
\cline { 2 - 4 } LEVANTADOS & CELULAR & FIXO & DADOS \\
\hline 1 & Bom & Não possui rede & Ruim \\
\hline 2 & Ruim & Não possui rede & Ruim \\
\hline 3 & Ruim & Não possui rede & Ruim \\
\hline 4 & Ruim & Não possui rede & Sem dados \\
\hline 5 & Regular & Não possui rede & Ruim \\
\hline 6 & Ruim & Não possui rede & Ruim \\
\hline 7 & Regular & Não possui rede & Ruim \\
\hline 8 & Muito ruim & Não possui rede & Muito ruim \\
\hline 9 & Regular & Possui rede & Ruim \\
\hline 10 & Ruim & Não possui rede & Ruim \\
\hline 11 & Regular & Não possui rede & Ruim \\
\hline 12 & Muito ruim & Possui rede & Ruim \\
\hline 13 & Regular & Possui rede & Ruim \\
\hline
\end{tabular}

FONTE: Martins, A. H. C. ; Filho, J. D. 2016.

\section{Considerações Finais}

Para os levantamentos realizados nas parcelas periféricas propostas neste trabalho, considerando pontos nas partes indicadas pela ANATEL onde não há indicação de cobertura pelas redes celulares e também carecem de adequada infraestrutura física das operadoras de telefonia fixa, feitos através de testes de cobertura utilizando o aplicativo opensignal e também através da verificação visual da presença física das redes das operadoras de telefonia fixa, constatou-se estas regiões e as pessoas que ali se encontram, estão desprovidas de atendimento para com os serviços e redes de telefonia, e quando ocasionalmente os tem através dos sinais das redes celulares que propagam livremente pelo espaço, são precários.

Na perspectiva da cidade, no sentido centro periferia, há um melhor atendimento das operadoras na porção central e precário na periferia. Neste mesmo sentido de atendimento, há uma sintonia entre melhores serviços de telefonia e o melhor perfil de renda, tendo ai, na perspectiva de consolidação do território, maior e melhor atendimento das operadoras de telefonia. Ainda, neste sentido, há um maior de construções, e também se observa um melhor visual das construções no sentido centro, o que pode considerar que o melhor atendimento das empresas privadas de telefonia se dará nas partes onde se visualiza maior renda.

Estas constatações identificam que a ocupação dos extremos da cidade é dada pela sociedade menos favorecida pela renda. Também se conclui que, nesta parcela do território, isto impacta na ausência ou na precariedade de atendimento das operadoras de telefonia. Observa-se ainda, que neste segmento segregado da cidade, o estado está distante de fazer seu papel de fiscalizador e gestor das políticas ao cidadão, e fazer com que haja um atendimento digno àqueles com maior vulnerabilidade social.

A expansão urbana desordenada, observada nos últimos anos, através da crescente investida do meio imobiliário, nas quais ocorreram diversos lançamentos de loteamentos, condicionaram a um aumento das periferias, o que desencadeia em um crescimento linear das infraestruturas necessárias ao atendimento à população, tais como água, energia elétrica, vias, e também, infra de telecomunicações. Esta crescente urbana, nem sempre se compatibiliza com o interesse das empresas privadas de telefonia, que nem sempre interessam em investir em toda cidade. Fica a critério das empresas, a análise de onde quando como e para quem investir, e se há interesse em atender, ficando assim o atendimento, predominantemente, naquelas parcelas do território de 
melhor status de renda.

Ficando assim, fora das redes e seus serviços, as regiões periféricas e aqueles ali se encontram.

\section{Referências}

AMPOS FILHO, C. M. Cidades brasileiras: seu controle ou o caos. 4 ed. São Paulo: Studio Nobel, 2001. $143 \mathrm{p}$.

ASSOCIAÇÃO BRASILEIRA DE NORMAS TÉCNICAS. NB 1350 - Normas para elaboração de plano diretor. Rio de Janeiro: ABNT, 1991.

BRASIL. Estatuto da Cidade: guia para implementação pelos municípios e cidadãos. 2 ed. Brasília: Câmara dos Deputados, Coordenação de Publicações, 2002.

CASTELLS, M. A galáxia da internet: reflexões sobre a internet, os negócios e a sociedade. Trad. de Maria L. X. A. Borges. Rio de Janeiro: Jorge Zahar, 2003.

JURADO DA SILVA, P. F. Cidades pequenas e indústria: contribuição para a análise da dinâmica econômica da região de Presidente Prudente - SP. 2011. 282 f. Dissertação (Mestrado em Geografia) Faculdade de Ciências e Tecnologia, Universidade Estadual Paulista, Presidente Prudente, 2011.

JURADO DA SILVA, P. F. Geografia das Telecomunicações no Brasil. 1 ed. São Paulo: Cultura Acadêmica, 2015.

MOYSÉS, A.; BORGES, E. A retomada dos financiamentos públicos imobiliários e a produção para os setores populares: impactos na reconfiguração espacial da RM de Goiânia. Rio de Janeiro: ANAPUR, 2011. p. 1-23.

SABOYA, Renato. Concepção de um sistema de suporte à elaboração de planos diretores participativos. 2007. 232 f. Tese (Doutorado em Engenharia Civil) - Universidade Federal de Santa Catarina, Florianópolis, 2007.

SANTOS, M. Espaço e Método. São Paulo: Nobel, 1988.

A natureza do espaço: técnica e tempo, razão e emoção. 4 ed. São Paulo: Edusp, 2008.

SILVA, J. A. Direito urbanístico brasileiro. São Paulo: Malheiros, 1995.

VILLAÇA, F. Dilemas do Plano Diretor. In: CEPAM. O município no século XXI: cenários e perspectivas. São Paulo: Fundação Prefeito Faria Lima - CEPAM, 1999. p. 237-247. 